\title{
LIBERTAD Y DESTINO COMO RECONOCIMIENTO DE LA MORAL EN LA FILOSOFÍA POLÍTICA DE DIEGO DE SAAVEDRA FAJARDO*
}

\section{FREEDOM AND FATE AS RECOGNITION OF MORAL IN THE POLITICAL PHILOSOHOPHY OF DIEGO DE SAAVEDRA FAJARDO}

\author{
Nora E. Nolasco Quiroz**
}

\section{Resumen}

Este texto recupera dos posiciones en torno al concepto de destino: la de Diego de Saavedra Fajardo y la de Plutarco. Ambos, a diferencia de algunos estoicos, sostienen que, independientemente de aquellas circunstancias que escapan a la voluntad humana (azar, contingencia y posibilidad), el hombre posee la capacidad para ser libre y tomar decisiones respecto de sus actos, sin que esto signifique dejar atrás el ideal del sabio. Para ellos, enfrentarse con el destino implica conocer las pasiones que se hallan inmersas en la naturaleza humana, así que no las toman en un sentido negativo. Por esta razón, ambos filósofos insisten en reorientar las pasiones a través de la educación, la moral o la religión $\mathrm{y}$, con ello, en dejar atrás la idea de que el hombre está determinado o bien por su propia naturaleza humana o por las circunstancias que se le presentan. De esta manera, brindan un reconocimiento esencial al ejercicio de la libertad humana.

\section{Palabras clave}

Libertad, determinismo, destino, pasiones, posibilidad.

\footnotetext{
* Artículo de investigación, cedido especialmente para esta publicación.

** Licenciada y maestra en Filosofía por la Facultad de Filosofía de la Universidad Veracruzana; ha sido profesora de Filosofía Política en esa misma facultad. Actualmente está cursando el Programa de Doctorado en Filosofía en el Instituto de Filosofía UV, y es profesora de Axiología de la Educación en la Maestría de Administración y Gestión Educativa de la Universidad del Golfo de México, campus Xalapa.
} 


\begin{abstract}
This paper recovers two positions on the concept of destiny: that of Diego de Saavedra Fajardo and that of Plutarch. Both authors, unlike some Stoics, say that regardless of circumstances beyond human will (chance, contingency and possibility), man has the ability to be free and make decisions about his actions, but this does not mean to abandon the ideal of the wise. For them, dealing with fate means knowing the passions that are embedded in human nature, so they do not take them in a negative sense. For this reason, both philosophers insist on redirecting the passions through education, morality or religion and, therefore, on leaving the idea that man is determined either by his own nature or by the circumstances presented to him. Thus, these authors provide essential recognition to the exercise of human freedom.
\end{abstract}

\title{
Keywords
}

Freedom, determinism, fate, passion, possibility.

\section{Introducción}

Como tema de reflexión, la libertad sigue siendo muy importante para el desarrollo de la filosofía política y moral, pues desde el momento en que aceptamos que somos seres sociales, también necesitamos saber hasta qué punto nuestra libertad no interfiere con la de los demás o, si es así, saber en qué criterios podemos basar esta interferencia.

La libertad puede ser tomada bajo diversas acepciones: moral, política, existencial u ontológica. Sin embargo, la acepción que importa en el campo de la política es la libertad en su sentido moral y político, pues se ha adoptado la idea de que el hombre necesita de ciertos reglamentos que ayuden a sobrellevar su condición social. Los siglos XVII y XVIII son ejemplo de esta preocupación: fue en esa época cuando se originaron las justificaciones que permitían entender a la libertad en sentido mecanicista y liberal. Ambas trataban de justificar la libertad del individuo desde una supuesta libertad natural, misma que pretendía ser legitimada desde la ley positiva y la ley moral.
No obstante, un problema que se deriva de estas dos posturas es saber si el hombre está determinado o no, a mantenerse dentro de la posibilidad de libertad para actuar de tal o cual manera, es decir, si él se halla enlazado a causas externas que lo obliguen a comportarse de cierta forma en una situación determinada. Ante dichas preocupaciones, también se suscitaron aquellas posturas que niegan la existencia de un libre albedrío y, con ello, de una voluntad que sirva como herramienta en la toma de decisiones, esto a partir de la creencia en una autodeterminación en el hombre en la que "la posibilidad coincide con la realidad y la realidad con la necesidad"' (Damm Arnal, 1989: 17).

Precisamente, el presente texto tiene la pretensión de retomar la discusión en torno a la libertad y al determinismo en el ámbito de la moral y la política desde la filosofía de Diego de Saavedra Fajardo ${ }^{1}$. Él pertenece al s. XVII y

1 Filósofo español perteneciente al siglo XVII, nació en las proximidades de la ciudad de Murcia, España, el 6 de mayo de 1584 y murió el 24 de agosto de 1648. Fue diplomático de profesión, crítico literario, poeta y jurista. 
en su filosofía podemos observar la discusión que, desde el estoicismo, se estableció sobre la libertad humana y el determinismo. En sus Empresas politicas ${ }^{2}$, nosotros podemos observar algunas líneas estoicas; por ejemplo, la idea de la providencia, aunque en el sentido cristiano. Pero él, al igual que Plutarco, deja un resquicio para expresar que el hombre es libre y que, mediante la educación, puede lograr un desarrollo de la libertad en el ámbito moral y político.

Para mostrar esto, recuperaremos algunos argumentos de Plutarco que coinciden con los del filósofo español. De igual manera, expondremos algunas líneas generales de la filosofía de Diego de Saavedra Fajardo, quien en su preocupación por la libertad no excluye la idea de una condición humana, sólo que a diferencia de algunos iusnaturalistas, él no es pesimista, ya que tiene una visión positiva de la condición humana, por la cual logra acercarse a la defensa de la libertad humana $\mathrm{y}$, con ello, a tomar una postura prudente respecto del determinismo.

\section{El destino en el ámbito moral como reflexión de la conducta humana}

No podemos negar que la reflexión sobre la política como actividad humana ha estado ligada a la reflexión moral desde la antigüedad. El ideal socrático del sabio es un reflejo de ello, ya que esta idea también refleja la aspiración del buen ciudadano: aquel que debe respetar las leyes y procurar la justicia. Este ideal fue adoptado, más tarde, por Platón y Aristóteles, quienes ante su insistencia porque los hombres se pudieran realizar plenamente en sociedad, reflexionaron sobre la justicia y la virtud, respectivamente.

2 Esta obra es la más reconocida de nuestro tratadista español y está compuesta por cien emblemas simbólicos que tienen como finalidad mostrar, mediante algunos signos, varias estrategias para la educación del príncipe.
El ideal del sabio socrático, como sabemos, indica aquella vida que muestra una congruencia entre el pensamiento y el obrar, es decir, el "conócete a ti mismo" nos descubre también el conocimiento sobre el bien, pues la virtud viene a ser identificada con la razón, y en este sentido, no puede obrarse mal a menos que sea por causa de la ignorancia. Como lo señala Antonio Gómez Robledo, en Sócrates se puede rastrear un concepto de razón ligada a la idea de la phrónesis, pues este concepto -que fue bien señalado por algunos intérpretes modernos- "designa conjuntamente la percepción intelectual y la vivencia amorosa. Quien, en efecto, sienta y ame el bien así, 'con toda su alma', como dirá Platón, no puede obrar el mal” (Gómez Robledo, 1994: 97).

Por otro lado, la escuela estoica también recupera el ideal socrático y la idea del bien, según Aristóteles. Sin embargo, a diferencia del Estagirita, ellos fundamentan su concepto de bien mediante la idea de "vivir conforme a la naturaleza", pues "la felicidad es también el fin de la vida; y la felicidad ha de ser equivalente a una vida que fluya suavemente [...] el fin, la fuente de la felicidad, es una cierta forma de vivir" (J. M. Rist, 1995: 12-13). Además, también sustentan que la naturaleza humana forma parte de la naturaleza del "todo", de ahí que "vivir conforme a la naturaleza" también signifique "vivir según la naturaleza de uno mismo y de todas las cosas, no haciendo nada de lo que prohíbe la ley común, que es la recta razón que recorre todas las cosas y es la misma para Zeus" (AA. VV., 1991: 20-21).

Los estoicos identifican a la ley común con el logos, pues es el que ordena racionalmente el universo, mismo del que participa el alma de cada hombre, y en este sentido, decir que el hombre debe vivir conforme a la naturaleza significa que él vive según el orden determinado por el logos o "razón del Universo". 
Pero, en esta participación que tiene el hombre del logos universal se sobreentiende que el hombre posee un fin humano y racional, es decir, un prototipo al que se debe aspirar, que es el ideal del sabio,

[...] el del sabio, que practica en todas las condiciones, aún las más adversas, la virtud, que no es otra cosa que la práctica consciente de vida conforme a la naturaleza. Es esa virtud la que produce, finalmente, la felicidad, regulando racionalmente nuestra conducta y protegiéndonos contra los males ajenos, los que no está en nuestras manos modificar, aquellos que nos depara adversamente la fortuna (AA. VV., 1991: 21).

Esta cuestión es reflejo de la preocupación política y moral de su tiempo, puesto que es el momento en que Alejandro Magno lleva a la práctica el proyecto de su padre Filipo II, es decir, logra unificar las ciudades-estado griegas bajo la hegemonía macedónica, y ante ello:

[...] el ciudadano se sentirá sujeto de unos derechos y unos deberes que ya no le constriñen a un pequeño ámbito político, como era el de la ciudad. Dentro de la nueva forma política, la monarquía helenística, el ciudadano formará parte de una comunidad mucho más amplia, integrada en ocasiones por pueblos con creencias, instituciones y lenguas diferentes (AA. VV., 1991: 11).

Por tal motivo, no puede parecernos extraño que los estoicos se interesaran por estas cuestiones políticas, pues además, también debemos tener en cuenta que en ese momento se presentaban conflictos sociales, debido a la situación de miseria en que se encontraban algunas poblaciones. Situación que, como la mayor parte del tiempo sucede, es un motivo para buscar cobijo dentro de las posturas filosóficas.

En este caso, los estoicos no sólo tuvieron una preponderancia por las cuestiones éticas, también estuvieron muy interesados por la física y la lógica, de tal manera que los temas de interés para ellos se relacionaban entre sí. Lo mismo ocurre con la cuestión del destino, ya que las implicaciones o resoluciones en torno a él también estuvieron tocadas por la física, la lógica y la ética. De ahí que el problema que se ha desatado en torno a las lecturas de los estoicos es saber si eran o no deterministas, pero en caso de decir que lo son, saber en qué sentido puede asegurarse tal cosa.

El problema del determinismo se logra observar desde el estudio de la lógica que llevan a cabo los estoicos, en el que el punto de partida es la preocupación por refutar el argumento de Aristóteles: "el argumento perezoso", que expresa que toda afirmación y toda negación es verdadera o falsa. Sin embargo, la implicación de este tipo de proposiciones, desde los estudios lógicos, se aplica también a los contingentes futuros, pues para Aristóteles no se pueden enunciar proposiciones sobre el futuro, porque los "hechos" aún no han ocurrido y, en ese sentido, las afirmaciones no se pueden referir a los acontecimientos mismos, por lo que no se puede decir que sean verdaderas.

De ello se sigue que aunque dado un par de afirmaciones contradictorias sobre el futuro, una u otra será verdadera o falsa, sin embargo de ningún enunciado particular se puede decir que sea verdadero o falso. Aristóteles añade entonces que un enunciado así puede ser más verdadero que 
otro, es decir, puede suceder con más probabilidad, según lo que podemos prever. Pero más verdadero no implica verdadero (J.M. Rist, 1995: 124).

Al parecer, de las proposiciones acerca de los contingentes futuros no se puede decir que sean verdaderas, por el hecho de que lo que ocurre en una situación particular podría no haber ocurrido. Pero, en tanto que aparece la noción de "lo posible", se logra refutar este argumento, porque "lo posible" significa que algo puede o no puede ocurrir. No obstante, estas cuestiones fueron discutidas entre Aristóteles y los megáricos, quienes opinaban que lo posible es posible en tanto que está ocurriendo, pero fue Diodoro Crono ${ }^{3}$, específicamente, quien pudo refutar la tesis del estagirita, y con ello, plantear las implicaciones de dichas proposiciones en el ámbito de la esfera moral.

Según Diodoro Crono,

lo posible no es simplemente lo que sucede, sino o bien lo que es cierto o lo que de hecho será cierto [...] Diodoro mantenía que todas las proposiciones, sean sobre contingentes futuros o no, son o verdaderas o falsas. Para Diodoro una proposición que sugiere algo imposible del futuro es falsa (J.M. Rist, 1995: 124).

Para él, estas proposiciones son incompatibles: "1) cualquier verdad acerca del pasado es necesaria, 2) lo imposible no se sigue de lo posible, por lo tanto, 3) que lo que ni es

3 Diodoro Crono fue uno de los fundadores de la Escuela de Megara, creada por Euclides de Megara. Fue un gran lógico y desarrolló “el argumento dominante" como contra-argumento del argumento de Aristóteles: el argumento perezoso. verdad ni será verdad es posible" (J.M. Rist, 1995: 127).

El rechazo que establece Diodoro se enfoca a la proposición 3), y lo hace con un análisis de la posibilidad a través de su argumento conocido como "el argumento soberano" (invencible, triunfante o dominante). En él, enuncia la inconsistencia o incompatibilidad de los tres enunciados anteriormente mencionados, pues al suponer como verdaderos los dos primeros y declarar inconsistente al conjunto, Diodoro deduce la falsedad del tercer enunciado, y con ello, la verdad de su negación: "lo que no es ni será es posible", por lo tanto, "lo que es o será posible". Con esta demostración creyó haber hallado un argumento invencible de su noción de posible, o más bien, creyó haber encontrado un argumento a favor de la fuerza invencible: el destino. De su noción de posible se deduce que lo que no ocurre es imposible y que lo que ocurre o ha ocurrido es necesario (primer enunciado).

Diodoro de Crono fue maestro de Zenón y Arcesilao $^{4}$, razón por la cual podemos justificar que el problema respecto de la "posibilidad" haya sido retomado por los estoicos. Aunque aquí no nos centraremos en las cuestiones lógicas en torno al concepto de posibilidad, pues lo que nos interesa es abordar el tema del destino y el determinismo en el ámbito de la moral. Es por ello que sólo hemos hablado del sentido lógico de este concepto muy someramente, pues debemos tener como antecedente esta discusión para entender lo que expresará Plutarco acerca del destino.

\section{El concepto de destino en Plutarco}

La ética estoica se funda en su determinismo cósmico porque, para los estoicos, la ley que

4 Debemos tener en cuenta que Zenón fue el iniciador del estoicismo y Arcesilao fue representante de la Escuela Media Platónica. 
rige el universo es el fuego inteligente o logos divino que toca nuestra alma, y ante tal determinismo cósmico, la actitud del sabio sólo es aceptar el destino, puesto que todo está regido por la providencia del logos. Para ellos, el universo está compuesto de dos principios: uno activo y otro pasivo, donde el pasivo se caracteriza por ser una materia, una sustancia sin cualidad; mientras que el activo está constituido por la razón; está en la materia y actúa en ella, "el activo, que es eterno y crea cada cosa a través de la materia, es dios mismo" (Cicerón, 2005, XXIII). De ahí que el principio activo esté identificado como un espíritu, que es consecuencia del fuego y de la actividad creadora, pues se le conoce como "fuego creador", como una fuerza vital que se expande por todo el universo.

En este sentido, la física es el fundamento de la ética, pues se muestra mejor con la máxima moral de los estoicos: "vive de acuerdo con la naturaleza" o, lo que es lo mismo, siguiendo al logos divino. Este acatamiento de la ley crea las bases de una ética del deber entendida a la manera intelectualista, puesto que el seguimiento de este deber sólo es posible por parte del sabio, porque él es quien conoce el logos. Sin embargo, a través de la aceptación del destino, puede alcanzarse el sosiego de ánimo propio del sabio.

En la filosofía estoica, los acontecimientos que tienen lugar en el tiempo obedecen a las leyes de la naturaleza, las leyes del destino, es decir, a la divina providencia. Por ejemplo, Crisipo tiene la intención de conciliar las leyes de la naturaleza con la responsabilidad moral, y deriva la justificación de la existencia de una secuencia de eventos que conllevan el acto de ciertos hechos, a la que nombra "destino": "El destino es una palabra para describir el estado de cosas que fue, es y será" (J. M. Rist, 1995: 131).
Pero por otro lado, Cicerón también señala que la cuestión del hado (destino) pertenece a la lógica y a la ética, y expresa, contrariamente a Crisipo, que si existe una concatenación de causas, éstas no tienen una influencia en los actos que dependen de la voluntad humana, pues "[...] si, en efecto, unos son más propensos a unas cosas y otros a otras, por causas naturales y antecedentes, no por ello también de nuestra voluntad y apetencias hay causas naturales y antecedentes, pues nada estaría en nuestra potestad, si así fuera la cosa" (Cicerón, 2005: 6).

También Plutarco se une a esta discusión en torno del destino. Plutarco exalta la existencia de la libertad humana frente al destino de los estoicos, ya que para él es imposible que el mundo derive de una causa única porque entonces esta causa única sería Dios, y en él es imposible la maldad, por ello, según él, debe existir otra causa que sea el origen de la existencia del mal, es una fuerza indeterminable que se identifica con el alma del mundo en rebeldía contra Dios. De esta manera sustenta una especie de dualismo, "llenado" por una serie de seres intermedios entre Dios, que es pura bondad, y el mundo, y que pueden identificarse con las diversas divinidades y "demonios" de las religiones populares.

Para Plutarco, el destino se entiende de dos maneras: como actividad y como substancia. En tanto actividad, el destino debe ser entendido como una ley que no puede transgredirse, ya que ella ordena a todo el universo, por lo que dice: "[...] podría definirse como un enunciado divino, intransgredible, merced a una causa que no se puede eludir; según se dice en el Timeo, como una ley que acompaña la naturaleza del universo, por la cual se rige lo que llega a existir" (Plutarco, 1996: 1-2). Y por otro lado, el destino como substancia es considerado como el alma entera del cosmos 
y se divide en tres partes: "en la parte fija, en la que se piensa errante y, en tercer lugar, en la que se encuentra bajo el cielo, alrededor de la tierra; de éstas, la más alta es llamada Cloto; la que está después de ésta, Átropos, y la que está más abajo, Láquesis” (Plutarco, 1996: 2).

En el destino entendido como actividad se dan los problemas físicos, éticos y dialécticos, según Plutarco; pero, esta parte del destino no deja de depender de su parte constitutiva: de la substancia. Esta relación la podemos inferir de la cualidad que Plutarco le impone al destino: la finitud. Él es finito porque, al ser una ley, no puede tener la cualidad de ser infinito, sin embargo, está en consonancia con los acontecimientos que son, a su vez, infinitos, pues dice: "Realmente, a pesar de que los acontecimientos, que se dan desde el infinito y hacia el infinito, son infinitos, el destino, que rodea todo en círculo, no es infinito, sino finito; en efecto, ninguna ley, ningún enunciado, ninguna cosa divina podía ser infinita" (Plutarco, 1996: 2-3).

Esta idea de la finitud del destino, Plutarco la deriva de Platón, quien en el Timeo explica el movimiento de los astros y del universo, y con base en ello, establece que el movimiento de la tierra está determinado por el movimiento de lo Mismo, ya que él determina que el movimiento se dé de la misma manera desde el principio hasta el fin. Y así dice Platón:

En cambio le atribuyó un movimiento apropiado a la forma de su cuerpo, de los siete movimientos el que se relaciona más estrechamente con la inteligencia y el pensamiento, quiso por consiguiente que el mundo girase sobre sí mismo y alrededor de un mismo punto con un movimiento uniforme y circular. Le rehusó los otros movimientos quitándole así los medios de errar de un lado a otro (Platón, 2009: 315).
La cuestión estriba en darse cuenta del papel que cumplen los acontecimientos en unión con el destino a través de la "revolución", es decir, en darse cuenta de que en ella podemos observar la repetición necesaria de los acontecimientos, pues ellos se encuentran subordinados al orden del cosmos, donde el tiempo, que es determinado y calculable, agrupa a todo, y cuando esta revolución haya terminado, el ciclo volverá a repetirse.

Ahora bien, ¿cuál es el papel del destino dentro de estas revoluciones? Primero que nada, debemos ser conscientes de que los acontecimientos al ser infinitos tienden a repetirse dentro de las ocho revoluciones de las que nos habla Platón, y que Plutarco recupera. No obstante, el destino al ser finito, tiende a ser interpretado por Plutarco como un círculo, por eso explica que el destino es "el enunciado de los sucesos circulares" (Plutarco, 1996: 4). Y el destino, así entendido, puede inferirse "como la ley del Estado, que, en primer lugar, ordena la mayoría de las cosas, aunque no todas, a partir de una hipótesis, y luego abarca universalmente, dentro de lo posible, los asuntos relacionados con la ciudad" (Plutarco, 1996: 4).

En la universalidad del destino como cualidad, Plutarco comienza a relacionar al destino con el azar, lo contingente y lo posible, ya que establece los parámetros para delimitar la libertad humana. La universalidad como cualidad de éste consiste en prescribir a las cosas de manera universal, pero con relación a las cosas individuales, éste no prescribirá

5 Respecto de la noción de "revolución" en el texto de Plutarco, se ha hecho hincapié en que de la interpretación de la palabra griega $\pi \varepsilon \rho i ́ o \delta o v$ en latín se tradujo como periodus o periodos, pero que no se utilizó en este texto como tal, porque ella se refiere sobre todo al tiempo como recorrido, es decir, "al tiempo recorrido", hecho por el cual se hace mención a revolución. 
que sean de una u otra forma, y para ello recurre a una explicación relacionada con la ley del estado, como a continuación se menciona:

La ley del estado prescribe consecuentemente acerca del guerrero distinguido y del desertor $\mathrm{y}$, de igual manera, acerca de los demás, pero no prescribe cómo es legal acerca de este o de ese individuo, sino que habla, en primer lugar, de las cosas universales, y, posteriormente, de las cosas que caen bajo aquéllas. Podríamos decir, pues, que es algo legal honrar a algún ciudadano sobresaliente y el castigar a algún otro que ha desertado, puesto que virtualmente la ley ordena acerca de las cosas, de la misma forma en que, por así decirlo, la médica y la gimnástica abarcan virtualmente los casos particulares mediante las prescripciones generales (Plutarco, 1996: 4).

Plutarco debate la idea de quienes consideran que los casos particulares son anteriores, en cuanto al orden se refiere, y que lo universal existe a causa de estos, pues se piensa que "el fin es anterior a algo que existe en función de él". Para Plutarco, el destino no contiene todas las cosas de manera clara, ya que sólo contiene los principios universales, por esta razón afirma que "lo determinado, que es propio del pensamiento divino, se considera más bien dentro de lo universal (tal es, en realidad, la ley divina y la del estado), y lo indeterminado se considera dentro de lo particular" (Plutarco, 1996: 5).

La idea de que "todo es según el destino" es para nuestro filósofo en parte cierto y en parte falso. Es verdadero en tanto que el destino abarca las "consecuencias" de los acontecimientos que suceden en torno a los hombres, la tierra y el cielo. Pero es falso en el sentido de que esta frase se refiera a aquellas cosas que son consideradas como "antecedentes" de los acontecimientos, puesto que hay cosas que dependen de nosotros, pues así lo explica:

[...] el "todo es según el destino"
no significa todo, sino sólo las con-
secuencias del destino, no hay que
decir que todo es según el destino,
aun cuando sea según el destino.
De manera que el destino abarca
todos los acontecimientos, pero no
es correcto decir que muchas de las
cosas que están en él, y, me atrevería
a decir, todas las que son anteceden-
tes, son "según el destino" (Plutarco,
1996: 5).

Ahora bien, de la relación que tiene el destino con el azar, lo posible y la providencia, Plutarco señala que estos elementos han de ser considerados como "antecedentes" porque pueden darse ellos mismos y, además, dan lugar al destino. En cuanto a lo posible, se dice que éste debe existir, como género, de manera previa a lo contingente y que, como materia, deberá ser anterior a lo que depende de nosotros. Sin embargo, para hablar de lo posible necesitamos retomar el concepto de "potencia" que ha señalado Aristóteles, ya que para Plutarco ésta es necesaria, pues se la entiende como algo intermedio que hace posible la creación de algo, pues dice: “[...] de la potencia y de lo potente y de lo posible, lo potente, en cuanto al ser, es anterior a la potencia, y la potencia existe previamente a lo posible". Por tanto, lo posible es "lo que llega a ser naturalmente de acuerdo con la potencia, y, más específicamente, como esto mismo, cuando no hay ningún impedimento externo frente al llegar a ser" (Plutarco, 1996: 7).

Y en cuanto a lo contingente y al azar, Plutarco expresa que lo contingente se diferencia de lo necesario, porque de este último, lo que sucede o su movimiento como tal jamás 
podrá ser impedido, mientras que lo contingente puede o no ocurrir y su opuesto es lo "posible". Así, "lo posible es, por naturaleza, anterior a lo contingente, y que lo contingente existe previamente a lo que depende de nosotros" (Plutarco, 1996: 9). Ahora bien, azar, contingente y necesario han sido deducidos por Plutarco de lo "posible", y como podemos darnos cuenta, aquí sigue latente aquella discusión en torno a "los mundos posibles"; no obstante, Plutarco no apela, por lo menos en este texto, a argumentos lógicos.

Por otro lado, el azar es una especie de causa, de donde se infiere que hay causas esenciales y otras accidentales. De las causas esenciales se puede decir que ellas están determinadas y son uno, mientras que las causas accidentales son indeterminadas y no se identifican con lo uno y, en este sentido, el azar está adherido a aquellas causas accidentales, sobre todo cuando están ligadas a la elección. Según Plutarco, los antiguos habían descrito al azar como una causa impremeditada y no evidente para el razonamiento humano, pero, y siguiendo la enseñanza de Platón, el azar puede ser una "causa accidental de las cosas que están en función de algo, en lo que es según una elección" (Plutarco, 1996: 9). Y, de acuerdo con lo anterior, para Plutarco lo raro y lo inesperado también están implícitos en lo accidental, por esta razón, lo que depende de nosotros es una parte de lo contingente y el azar es una parte de lo espontáneo.

Respecto a la Providencia, Plutarco ha señalado una tercera Providencia ${ }^{6}$, es decir, él ha divido a la Providencia en tres partes. La primera providencia es la inteligencia o voluntad del primer dios, que es, además, bienhechora de las cosas; la segunda es la de los dioses secundarios que se mueven en el cielo y hacen ordenadamente las cosas mortales y lo que se

$6 \quad$ Esta idea Plutarco la recupera de Platón. Véase Timeo o de la Naturaleza. relaciona con la permanencia y preservación de cada uno de los géneros. Y, por último, la tercera es aquella que es previsora de todos los demonios colocados en la tierra, es decir, como supervisor de los actos humanos.

Cabe mencionar que, para Plutarco, el destino está subordinado a la providencia: "El destino es totalmente según la providencia, pero la providencia de ninguna manera es según el destino" (Plutarco, 1996: 12). La providencia es más antigua que todas las cosas, excepto de aquel quien la creó, pues ella es propia del demiurgo o padre de todas las cosas; pero, a la par podemos preguntarnos por qué causas el compositor compuso el devenir y todo el universo. Él era bueno y en lo bueno no hay evidencia para la envidia, por ello, él quiso que todas las cosas se hicieran en el más alto grado, semejantes a él. Por esta razón se debe considerar que todas las cosas, incluso las almas humanas, están conformadas según la primera providencia que, en el momento de crear todo según su semejanza, también les dotó de las leyes del destino, pues “¿quién no pensaría expresa y clarísimamente que ello manifiesta al destino como una base y un código político que acompaña a las almas humanas, del cual él ofrece en seguida la razón?” (Plutarco, 1996: 7).

Con respecto a la segunda providencia, que es la de los dioses secundarios, ella se encargó de sembrar en la tierra otros elementos del tiempo, puesto que añadió al alma humana la guía, según sus posibilidades, de gobernar de forma bella y hábilmente al animal mortal, excepto que él mismo llegara a ser causa de males para sí mismo. Y es, precisamente aquí, donde Plutarco enlaza a la tercera providencia, pues decir que "a fin de no ser responsable de la maldad de cada uno de ellos" significa que el destino está enlazado a la naturaleza humana en tanto que permite que el hombre realice sus propias actividades impulsado por la providencia de 
su creador, y como recordaremos, el destino, al hallarse como especie de "antecedente", tiende a dar libertad a los seres humanos en torno a la elección de sus fines. Si el hombre está creado en concordancia con la primera providencia, lo ideal es que se oriente por la idea de bien, es decir, que tenga por finalidad el bien. Sin embargo, al estar en unión con la tercera providencia: la de los demonios, que en este caso se relaciona con las "pasiones", el hombre puede errar en seguir el mandato de la primera providencia. Por esta razón, "el que constriña a alguien la potencia demoníaca debe ser colocado en la tercera providencia, y el "progresar rápida e inmediatamente", en el destino, y el conjunto como tal, evidentísimamente es una especie de destino" (Plutarco, 1996: 14). Es decir, deberá acatar su destino, como sabio, para liberarse de la potencia demoníaca: sus pasiones.

\section{El destino como orientación moral en la política de Diego de Saavedra Fajardo}

La obra de Diego de Saavedra Fajardo recupera la posición estoica respecto de la moral y la ética, pues mediante ellas, el filósofo español expone la preocupación por formar la personalidad de un príncipe en relación a su gobierno; su filosofía política muestra una gran preocupación por conectar a la política, a la educación y a la moralidad. Empresas políticas es considerada como su obra principal y también se le conoce como manual de príncipes, porque expone la forma en que se debe educar al príncipe para que oriente a su pueblo hacia el bien común. Por esta razón, ella también puede ser catalogada dentro del nacimiento del Estado moderno, puesto que durante la época barroca, al menos en España, hubo contribuciones con este nacimiento a través de obras literarias que expresaban sus inquietudes morales y éticas respecto del comportamiento de los hombres y los gobernantes. Aunque ellos, a diferencia de los iusnaturalistas clásicos, no describieron una condición de la naturaleza humana basada en explicaciones científicas, lo que les permitió retomar a los clásicos: Platón, Aristóteles, Cicerón, entre otros, y con ello, también recuperaron las preocupaciones clásicas respecto a la ética, es decir, consideraron la preocupación por describir la manera en que el hombre podía acceder a la virtud.

A Diego de Saavedra Fajardo también se le conoce como un escritor antimaquiavelis$\mathrm{ta}^{7}$, pues su filosofía es contraria a la teoría política propuesta por el florentino, sobre todo contra aquella idea de razón de Estado expuesta en el Príncipe. Y es que, según Maquiavelo, la actividad política está sujeta a la "fortuna", que para él es variación, variación que podemos hallar con facilidad en la naturaleza humana, motivo por el cual, el príncipe debía tener en cuenta a la virtù, ya que sólo así podía ser amigo de la fortuna y recibir los beneficios de ésta. No obstante, esta postura maquiavélica trajo consigo el cuestionamiento de la virtud clásica, pues para él, el príncipe que actúe mediante ella, no siempre recibirá el beneficio de la fortuna. Y es que a veces, según Maquiavelo, el príncipe debe ser astuto y valerse de las circunstancias para mantener el poder político consigo, pues explica:

Se concluye entonces que, como la fortuna varía y los hombres se obstinan en proceder de un mismo modo, serán felices mientras vayan de acuerdo con la suerte e infelices cuando estén en desacuerdo con ella. Sin embargo, considero que es preferible ser impetuoso y no cauto,

7 Sin olvidar, también que Pedro de Rivadeneira, Claudio Clemente y Francisco de Quevedo están dentro de esta clasificación, pues sus escritos literarios y políticos fueron una reacción en contra de la teoría política de Nicolás Maquiavelo. 
porque la fortuna es mujer y se hace preciso, si se la quiere tener sumisa, golpearla y zaherirla. Y se ve que se deja dominar por éstos antes que por los que actúan con tibieza. Y, como mujer, es amiga de los jóvenes, porque son menos prudentes y más fogosos y se imponen con más audacia (Maquiavelo, 2010: 66).

Esta postura causó incomodidad a los tratadistas españoles puesto que no aceptaron la idea de valerse de la virtù para enfrentarse al destino, pues ante todo, el príncipe debía estar al servicio del fin, pero en un sentido moral que, en el caso de Diego de Saavedra, es la justicia, y por ello también puede valerse de la phrónesis. Asimismo, también debemos señalar que la idea de desorden en la que Maquiavelo instauró su nueva reflexión política fue otro motivo de incomodidad, pues para los tratadistas españoles esta idea no era correcta, ya que ellos establecieron sus reflexiones en torno a la idea de una providencia. En Diego de Saavedra Fajardo, se trataba de una providencia divina, de la cual emana la idea de orden y de destino, pues así lo señala en Empresas politicas:

La mayor potestad desciende de Dios. Antes que en la tierra, se coronaron los reyes en su eterna mente. [...] Tenga, pues el príncipe siempre fijo su ceptro, mirando a la virtud en la fortuna próspera y adversa; porque en premio de su constancia, el mismo Sol divino, que o por castigo o por exercicio del mérito permitió su menguante, no retirará de todo punto su luz, y volverá a acrecentar con ellas su grandeza. [...] Con el mismo símbolo quisiera Maquiavelo a su Príncipe, aunque con diversa significación, que estuviese en las puntas de su ceptro la piedad y impiedad para volvelle, y hacer ca- beza de la parte que más conviniese a la conservación o aumento de su Estado. Y con este fin no le parece que las virtudes son necesarias en él, sino que basta dar a entender que las tiene; porque, si fuesen verdaderas y siempre se gobernase por ellas, le serían perniciosas, y al contrario, fructuosas si se pensase que las tenía; estando de tal suerte dispuesto, que pueda y sepa mudallas y obrar según fuere conveniente y lo pidiere el caso (Saavedra Fajardo, 1988: 121-122).

Por esta razón, y a diferencia de Maquiavelo, Diego de Saavedra sí insiste en la idea de orden, porque para él, la política sigue estando en concordancia con el orden de la providencia divina. Así lo advierte en la introducción de Empresas políticas: "Pero las máximas principales de Estado confirmo en esta impresión con testimonios de las Sagradas letras, porque la política que ha pasado por su crisol es plata siete veces purgada y refinada al fuego de la verdad. ¿Para qué tener por maestro a un étnico o a un impío, si se puede al Espíritu Santo?" (Saavedra Fajardo, 1988: 9). Así pues, él considera a la comunidad política como un organismo vivo, cuyos miembros cumplen funciones distintas pero todas básicas, pues todo colabora con el todo. En este sentido, Saavedra Fajardo recupera la visión aristotélica en tanto que cree que los hombres tienden a establecerse en sociedad por naturaleza, ya que considera, de igual manera que el estagirita, que el hombre es impulsado por su propia naturaleza en la búsqueda del bien o la felicidad en sociedad.

Saavedra Fajardo, y al parecer Maquiavelo, tienen en consideración que el destino puede ser forjado por el hombre mismo; ambos están de acuerdo con la posición no sólo de Plutarco, sino también de Cicerón, en decir que los antecedentes dependen del obrar hu- 
mano, pues en el caso de Saavedra Fajardo, el curso del destino depende, sobre todo, de la phrónesis inducida a través de la educación; y en Maquiavelo, de la astucia.

Al respecto, Saavedra expresa que "No siempre la Providencia divina obra con los medios naturales, y si los obra, consigue con ellos diversos efectos, y saca líneas derechas por una regla torcida, siendo dañoso al príncipe lo que había de serle útil" (Saavedra Fajardo, 1988: 193). Sin embargo, y como se ha insistido, la phrónesis ${ }^{8}$ debe ser una guía en la actividad política del príncipe, pues dice:

Es la prudencia regla y medida de las virtudes; sin ella pasan a ser vicios. Por esto tiene su asiento en la mente, y las demás en la voluntad, porque desde allí preside a todas. Deidad grande la llamó Agatón. Esta virtud es la que da a los gobiernos las tres formas, de monarquía, aristocracia y democracia, y les constituye sus partes proporcionadas al natural de los súbditos, atenta siempre a su conservación y al fin principal de la felicidad política. Ancora es la prudencia de los Estados, aguja de marear del príncipe. Si en él falta esta virtud, falta el alma del gobierno (Saavedra Fajardo, 1988: 185).

Nuestro tratadista español entiende por destino a los "temporales" que se presentan en la actividad política, es decir, a ese conjunto de circunstancias que escapan a la voluntad del príncipe, y aunque no lo describe de la

$8 \quad$ Para Diego de Saavedra Fajardo la phrónesis no es la única virtud que debe tener en cuenta el príncipe dentro de su educación, ya que también debe valerse de la templanza, de la justicia y la fortaleza, puesto que, sobre ellas, se edifica la personalidad del príncipe. De ahí que las denomine "virtudes cardinales", pues ellas son el sustento de un gobierno sano. misma manera en que lo hace Plutarco, sí hace énfasis en que el príncipe debe vencer tal fortuna mediante la phrónesis, pues sólo a través de ella se puede conservar el orden en su principado. Esta idea se nos presenta de manera más precisa cuando señala que:

Toda la sciencia política consiste en saber conocer los temporales y valerse dellos, porque a veces más presto conduce al puerto la tempestad que la bonanza. Quien sabe quebrar el ímpetu de la fortuna adversa, la reduce a próspera. El que, reconocida la fuerza del peligro, le obedece y le da tiempo, le vence (Saavedra Fajardo, 1988: 232).

La importancia que Diego de Saavedra le brinda a los temporales la podemos observar en la insistencia con la que recurre a los ejemplos de gobernantes o héroes mitológicos con los cuales se ha investido la historia. Así, la historia es para él una herramienta útil en la educación del príncipe, ya que mediante ella se pueden observar los errores del pasado y prevenirlos en un futuro: "la historia es una representación de las edades del mundo. Por ella la memoria vive los días de los pasados. Los errores de los que ya fueron advierten a lo que son. Por lo cual es menester que busque el príncipe amigos fieles y verdaderos que le digan la verdad en lo pasado y en lo presente" (Saavedra Fajardo, 1988: 186). Y en este sentido, el papel principal de la historia será ayudar al príncipe a elaborar juicios con la ayuda de la phrónesis para orientarse hacia el bien común.

\section{Naturaleza humana y defensa de la libertad en Plutarco y Diego de Saavedra Fajardo}

Ahora bien, no podemos hablar de filosofía política sin tener en cuenta el estudio en torno al hombre, es decir, no podemos afirmar 
que la filosofía política esté desligada de la antropología filosófica, puesto que es el hombre quien lleva a cabo la formación de sociedades persiguiendo un fin en común: el bien. Este vínculo puede observarse desde la antigüedad, pero el Renacimiento también nos muestra una ligadura entre política y antropología filosófica, pues durante esta época "se inicia la exaltación de la libertad humana y de la responsabilidad civil del individuo" (Annunziata Rossi, 2009: 9).

Aunque se tiene a Italia como un país privilegiado porque en ella se da el auge del Renacimiento, debemos apreciar que en España también florecieron los estudios en torno al hombre y su naturaleza, pero con un énfasis distinto, ya que la antropología, por lo menos en Diego de Saavedra Fajardo, está cimentada desde la moral y la religión católica, y no en la ciencia. No obstante, no podemos negar que haya existido un desconocimiento sobre la explicación antropológica desde la ciencia, y más aún, que se hayan desconocido las implicaciones del Renacimiento en el resto de Europa, ya que desde el Medioevo se comenzó a buscar una explicación sobre la relación entre la vida activa y la vida contemplativa, misma que se observa, sobre todo, con Francisco Petrarca, poeta pre-humanista que se interesó por darle explicación a la lucha constante entre la conciencia religiosa y la conciencia mundana.

Con la preocupación que presenta Petrarca se hace una recuperación de Platón, y con él, de su idealismo, pues Petrarca creía que "la vida contemplativa no es aislamiento sino búsqueda de la interioridad para una caritas más eficaz; la vida contemplativa lleva al conocimiento y al contacto con Dios, pero no tiene que excluir la participación activa al servicio del bien común" (Annunziata Rossi, 2009: 14). La filosofía platónica es útil a Petrarca porque desde ella justifica la participación del hombre en la vida civil, (Petrarca, 1998: 21). Además, gracias a ello se logra conocer a la filosofía platónica durante el predominio de la filosofía escolástica. La filosofía debía promover la renovatio y es por ello que los humanistas prefieren investigar sobre los grandes problemas morales y dirigen su mirada hacia la ética, la política, la estética y todo aquello que esté relacionado con la vida práctica.

En el caso de España, aunque venía a la par del nacimiento de la ciencia moderna $y$, en específico, de la modernidad como tal, en ella, "se bloqueaba un desenlace totalmente moderno", pues si la Reforma fue un desafío para el mundo católico, España mantenía "un rechazo a sus consecuencias ideológicas, vivía la imposibilidad de insertarse completamente en el cambio. Encarnaba una ambivalencia cuya naturaleza e historia tenían que ver con la elección civilizatoria que España había hecho entre los siglos XV y Xvi" (Kuri Camacho, 2008: 77). Y por esta razón, nosotros podemos justificar que la explicación antropológica no venga cimentada de forma científica, como en el caso de Thomas Hobbes o John Locke, ya que Diego de Saavedra Fajardo toma en cuenta a la idea del conocimiento con la finalidad de explicar la flaqueza humana con la que convive el hombre en su interior, pues esta idea se deriva de su postura católica.

Sin embargo, en esta explicación el filósofo sí alude a la relación sujeto-objeto y, además, explica que el conocimiento proviene de los sentidos tanto internos como externos; ambos sufren variaciones que pueden causar incertidumbre y diferentes opiniones en los hombres, puesto que estos sentidos tienen una implicación en los humores de los individuos que no necesariamente pueden conducirle a la ciencia, porque estas opiniones contribuyen, por lo general, a la mera opinión de las cosas. 
Ahora bien, Diego de Saavedra Fajardo parte de una idea de la imperfección en la naturaleza del hombre, sobre todo en el príncipe, $\mathrm{y}$ dice que los afectos nacen con el hombre, pero que una vez que son reconocidos por la voluntad, se muestran con una falsa apariencia del bien; pero, una vez que la razón logra orientarlos echando mano del tiempo y de la experiencia, se puede reconocer el imperio de la razón sobre los afectos:

Tenemos por virtudes los vicios, queriendo que la ambición sea grandeza de ánimo; la crueldad, justicia; la prodigalidad, liberalidad; la temeridad, valor; sin que la prudencia llegue a discernir lo honesto de lo malo, y lo útil de lo dañoso. Así nos engañan las cosas, cuando las miramos por una parte de los anteojos de nuestros afectos o pasiones; solamente los beneficios se han de mirar por ambas. Los que se reciben parezcan siempre muy grandes; los que se dan, muy pequeños (Saavedra Fajardo, 1988: 56).

El concepto de "imaginación o fantasía" no tiene cabida en la descripción de las pasiones humanas que elabora Saavedra Fajardo, puesto que no se apega a ninguna explicación cientificista, más bien se puede observar que nuestro tratadista español formula una especie de perspectivismo en tanto que el príncipe juzga las cosas según sus pasiones o intereses se las muestren. No obstante, Saavedra Fajardo parte de la idea aristotélica de que nuestras acciones tienden siempre a una especie de bien, pero que al desconocer el significado de ese bien, nos equivocamos en la elección. Por otro lado, también debemos señalar que su antropología filosófica está orientada sobre todo a la personalidad del príncipe, pero esta postura no excluye la preocupación del hombre en general: al sostener la idea de que la educación puede reorientar las pasiones, él no niega que la educación sea accesible a los demás, aunque sí persiste en que la educación del príncipe debe ser lo más cautelosa posible con respecto a las pasiones, pues de ella depende la salud de su pueblo.

Diego de Saavedra Fajardo no divide a la providencia en tres partes, como lo estableció Plutarco, pero sí se puede lograr un acercamiento en ambas filosofías en lo que a las pasiones se refiere, pues recordemos que para Plutarco ellas no dependen de los dioses secundarios ni mucho menos de la Providencia primera, más bien dependen de los demonios que se han establecido en la tierra, y que el hombre, para poder liberarse de ellos, ha de poner todo su empeño para lograrlo, pues dice que debe "progresar rápida e inmediatamente, en el destino, y el conjunto como tal, evidentísimamente es una especie de destino". Mientras que Diego de Saavedra considera que ellas son el origen de la flaqueza y debilidad humana, puesto que son parte de su constitución imperfecta, porque para él, el único ser perfecto es Dios.

Buscar la manera de superar esos "demonios o pasiones" es la finalidad de ambas filosofías, ya que los dos tienen la intención de "sostener en el combate la virtud y la fortuna" (Plutarco, 1971: 19), puesto que dentro de este combate se hallan inmersas las pasiones humanas, pero en un sentido distinto del que consideraban los estoicos, pues tanto para Plutarco como para Saavedra Fajardo, las pasiones no son una enfermedad, "sino una potencia del alma: a la voluntad, dirigida a la razón, incumbe gobernarla, ir convirtiéndola, mediante una gradación de esfuerzos, en un resorte indispensable: crear, en suma, un hábito del bien" (Plutarco, 1971: 20). En nuestro tratadista español no existe pretensión por eliminar totalmente las pasiones, ya que está consciente de que ello es imposible, y por eso opta por buscarles una reorientación mediante la educación y la religión, pues se 
ha dado cuenta de que algunos vicios o pasiones pueden ser tomados de manera positiva y que pueden ser de utilidad al príncipe en ciertos casos, y así lo dice:

No es mi dictamen que se corten los afectos o que se amortigüen en el príncipe, porque sin ellos quedaría inútil para todas las acciones generosas, no habiendo la naturaleza dado en vano el amor, la ira, la esperanza y el miedo. Los cuales, si no son virtud, son compañeros della, y medios con que se alcanza y con que obramos más acertadamente. El daño está en el abuso y desorden dellos, que es lo que se ha de corregir en el príncipe, procurando que en sus acciones no se gobierne por sus afectos, sino por la razón de Estado (Saavedra Fajardo, 1988: 57).

Y en el caso de Plutarco, él sigue las líneas socráticas del conocimiento y del dominio de sí mismo, procura estructurar una moral basada en una generalidad, es decir, ella debe adaptarse a todos los hombres, no importando sus condiciones sociales. Ambos, al perseguir esta finalidad, se valen de la historia con grandes ejemplos que muestran no sólo el valor de los héroes, sino también las características que posee el hombre virtuoso. Sin embargo, lo importante de ambas filosofías respecto de las pasiones es que ambos pensadores tienen confianza en que la conducta humana puede orientarse mediante la ética y la moral, y aunque son conscientes de que las leyes civiles también son necesarias, aceptan que la ética y la moral son vías alternas, de vital importancia, para la educación en el hombre, y con ello, también aceptan que haya una moderación entre lo legal y lo moral, es decir, que el gobernante tenga en cuenta que la libertad del individuo sirve para decidir sobre qué tipo de leyes necesita en su con- vivencia social, pues en el caso de Diego de Saavedra, la idea del temor al soberano o al estado no existe, en tanto que no considera que los individuos sean ingobernables con la sola ley natural.

\section{Reflexiones finales}

El destino como tema de reflexión en la filosofía es muy amplío, pero es muy importante tenerlo en cuenta para la relación que se da entre la ética y la política, ya que de ella se deriva otra relación: la relación entre libertad y determinismo. Esto es de especial cuidado porque hay quienes han justificado la existencia del determinismo y han elaborado aseveraciones excesivas que permiten la justificación de ciertas acciones y discursos culturales o políticos. Pero, y como pudimos observarlo en Diego de Saavedra Fajardo y Plutarco, no podemos aventurarnos en hacer tales afirmaciones, pues existe en nosotros un espacio para la deliberación de nuestros actos. Así lo han marcado estos filósofos en sus reflexiones. Ellos, además, perciben que la historia es una herramienta útil para la clarificación de la relación libertad-determinismo, pues no sólo viene a presentarse como ejemplo, sino también como norma, donde el destino, aunque debe cumplirse, permite la acción libre del hombre mediante el azar, la contingencia y la posibilidad; tal es la relación que impone Plutarco entre “acontecimientos" y "destino".

Como pudimos darnos cuenta, tanto la providencia como las leyes civiles pueden determinarnos en cierto sentido, pero la capacidad de decisión o deliberación en el hombre está latente, pues al ser éste el autor de sus "antecedentes" en el devenir de la fortuna, se sigue que lo "consecuente", en cierto modo, sí depende de él, a la par de las circunstancias que se le presenten. Por esta razón, el hombre debe estar al cuidado en la 
educación de sus pasiones porque ellas no necesariamente nos conducen al error. Diego de Saavedra cree que, de vez en cuando, ellas pueden orientarnos en no vacilar respecto de los "antecedentes" en las acciones morales, evitando así culpar al destino de lo sucedido.

Por otro lado, la idea de condición humana que ha manifestado Diego de Saavedra Fajardo es crucial porque permite romper con la idea de condición humana negativa, con la idea de que las pasiones nos determinan para actuar de manera egoísta ante los demás, y de que no hay posibilidad de cambiar el destino respecto de nuestra conducta en sociedad, por lo cual necesitamos de un poder político que inspire el miedo más que la confianza.

Podemos decir, por tanto, que la noción de libertad que expresa Diego de Saavedra Fajardo se presenta de una manera positiva, pues el príncipe no sólo debe velar por sus intereses personales, antes debe estar al pendiente del bienestar de los ciudadanos o súbditos, y dentro de este bienestar, está la obligación de tomar en cuenta al súbdito como "persona", es decir, como alguien que posee libertad y capacidad de decisión. El papel de la religión y la moral es enseñarle al príncipe esa responsabilidad. Por este motivo, la moral y la religión también son necesarios para el desarrollo de la autonomía en los espacios en que se desarrolla la vida de la persona: el privado y el público. Sin embargo, lejos de admitir prioridades entre libertad o determinismo, debemos cuestionarnos qué es lo que pretendemos ante la defensa de uno $u$ otro, pues ante el actual panorama relativista, tanto la defensa del determinismo y de la libertad en exceso brinda un apoyo para evadir responsabilidades éticas y morales en las acciones políticas sobre ciertos hechos actuales, por ejemplo, ante la violencia o, simplemente, ante un mal gobierno. De ahí que la insistencia radique en buscar aquellos elementos que nos hagan clara la presencia de nociones tan importantes y fundamentales para la consolidación de los gobiernos, como es el caso de la democracia.

\section{Referencias}

AA. VV. (1991). Antología de los primeros estoicos griegos. (Traducción de Martín Sevilla Rodríguez). Madrid: Akal.

Cicerón. (2005). Del hado. (Versión de Julio Pimentel). México: Bibliotheca Scriptorum Graecorum et Romanorum Mexicana, UNAM, Coordinación de Humanidades, Programa Editorial.

Damm Arnal, A. (1989). Libertad: esencia y existencia. Una aproximación al estudio de la libertad. México: Editora de Revistas.

De Saavedra Fajardo, D. (1988). Empresas políticas. (Edición, introducción y notas de Francisco Javier Díez de Revenga). Barcelona: Editorial Planeta.

Gómez Robledo, A. (1994). Sócrates y el socratismo. México: FCE.

Kuri Camacho, R. (2008). El barroco jesuita novohispano: la forja de un México posible. México: Universidad Veracruzana.

Maquiavelo, N. (2010). El príncipe. (Precedido por Nicolás Maquiavelo en su $5^{\circ}$ centenario por Antonio Gómez Robledo). México: Editorial Porrúa "Sepan cuantos...".

Platón. (2009). Diálogos. (Estudio preliminar de Francisco Larroyo). México: Editorial Porrúa "Sepan cuántos...".

Plutarco. (1971). Alejandro y César. España: Biblioteca Básica Salvat. 
Plutarco. (1996). Acerca del destino. (Versión de Pedro C. Tapia Zúñiga y Martha E. Bojórquez Martínez). México: Bibliotheca Scriptorum Graecorum et Romanorum Mexicana, UNAM, Coordinación Humanidades, Programa Editorial.

Rist, J. M. (1995). La filosofía estoica. Barcelona: Crítica. 